\title{
AUTORITARISMO E DEMOCRACIA EM PERSPECTIVA: O GOLPE DE 1964 NO BRASIL ATRAVÉS DA IMPRENSA COLOMBIANA
}

\author{
Elaine Schmitt ${ }^{1}$ \\ Nashla Dahas ${ }^{2}$
}

\section{Introdução}

São já conhecidos no Brasil os estudos sobre os impactos do golpe civil-militar de 1964 sobre a grande imprensa, como a censura e as perseguições políticas, além das pesquisas que discutem o apoio de alguns jornais de grande circulação ao acontecimento, tais como O Estado de São Paulo, a Folha de São Paulo e O Correio da Manhã ${ }^{3} \mathrm{Na}$ tentativa de buscar novos olhares sobre o golpe brasileiro, este artigo apresenta os discursos produzidos pela imprensa colombiana entre março e maio de 1964. Serão analisadas as capas de um periódico de grande circulação, apontando, assim, para o destaque produzido pelo jornal ao acontecimento no Brasil. Acreditamos que este seja um passo no caminho para a expansão do quadro de análise histórica, que possibilitará a compreensão mais ampla das influências midiáticas e inter-relações entre os países vizinhos durante a década de 1960. Sendo assim, o artigo coloca a seguinte questão: como um dos jornais da grande imprensa colombiana retratou discursivamente o golpe civil-militar brasileiro? Faremos ainda uma apresentação panorâmica do 'estado da arte' da imprensa e do cenário político colombiano naquele momento.

Partimos da importância da grande imprensa para a construção de um imaginário compartilhado pelo senso comum a respeito de acontecimentos considerados importantes para a vida local ou nacional. Além disso, é possível verificar e avaliar o esforço dessas empresas da comunicação no sentido da construção de certas memórias coletivas ${ }^{4}$ a respeito destes mesmos eventos.

Seguimos as contribuições de José D'Assunção Barros ${ }^{5}$, ao apontar para comparação como método de análise que visa a iluminar um objeto ou situação a partir de outro, frequentemente mais conhecido, permitindo a confecção de analogias, assim como a identificação de semelhanças $e$ diferenças entre duas ou mais realidades. Além de tais gestos considerados quase intuitivos da operação histórica, Barros sugere que a História Comparada implica um processo autocrítico $e$ autorreflexivo para o qual contribuem essencialmente as seguintes questões: "o que se pode comparar" e "como se compara".

Em conformidade com a especificidade de nosso tema, também faremos uso da proposições de Maria Ligia Coelho Prado ${ }^{6}$, em artigo dedicado à repensar a história comparada da América Latina. Segundo a autora, a história comparada deve fugir das justaposições e das classificações, mas também não deve estar comprometida com a busca de generalizações. Tratar-se-ia eminentemente de compreender as convergências $e$ as particularidades das circunstâncias históricas e dos sujeitos em questão.

\footnotetext{
${ }^{1}$ Mestre em jornalismo pela Universidade Estadual de Ponta Grossa e doutoranda pelo Programa Interdisciplinar de Ciências Humanas da Universidade Federal de Santa Catarina. Contato: elaine.schmitt@gmail.com.

${ }^{2}$ Doutora em História pela Universidade Federal do Rio de Janeiro, e pós-doutoranda e professora colaboradora do Programa de Pós Graduação em História do Tempo Presente da Universidade do Estado de Santa Catarina. Contato: nashladahas@hotmail.com.

${ }^{3}$ FICO, Carlos. Ditadura militar brasileira: aproximações teóricas e historiográficas. Tempo e Argumento, Florianópolis, v. 9, n. 20, p. 5, 74. jan./abr. 2017.; ABREU, Alzira A. A modernização da imprensa (1970-2000). Rio de Janeiro: Jorge Zahar, 2002.

${ }^{4}$ HALBWACHS, Maurice. A memória coletiva. São Paulo: Vértice, 1990.

${ }^{5}$ BARROS, José D'Assunção. História Comparada: da contribuição de Marc Bloch a constituição de um moderno campo historiográfico. História Social, n.13, p. 7-21, 2007.

${ }^{6}$ PRADO, Maria Ligia Coelho. Repensando a história Comparada da América Latina. Revista de História 153 (2 - 2005$)$, 11 33.
} 


\section{A imprensa colombiana: um breve histórico}

Pode-se dizer que durante todo o século XIX, o jornalismo colombiano se caracterizou pela politização, muitas vezes, de caráter doutrinário e/ou como forma de resistência ou revolta. Nesse período, houveram mais de 800 "diários" ou folhas que circularam em maior ou menor escala. A historiografia mostra como o percurso do jornalismo nacional esteve, desde então, atrelado à história dos dois partidos tradicionais do país: o Partido Liberal e o Partido Conservador, que surgiram em meio à guerra civil nos anos quarenta daquele século. Gradativamente, a imprensa abandonou traços mais personalistas para defender os interesses de um ou de outro partido. ${ }^{7}$

Ao menos até a década de 1950, o jornalismo colombiano sofreu inúmeras influências ocasionadas pelas transformações globais ligadas a expansão da industrialização como forma de vida na América Latina. Internamente, o fim do século XIX e o começo do XX, também registrou o início um processo de modernização técnica da imprensa, sempre acompanhado da mencionada partidarização da produção de notícias. Este modelo se consolidou durante os governos da Frente Nacional (19581974), que, de acordo com Prieto ${ }^{8}$, trouxe variadas repercussões em projetos jornalísticos, tanto para as folhas que eram contra, quanto para os que eram a favor desse acordo político entre liberais $e$ conservadores. As colocações do autor nos ajudam a compreender tanto aquele contexto político, quanto as suas relações com a imprensa colombiana da época:

Sus repercusiones aún suscitan debates, ya sea por el carácter excluyente del acuerdo o por el celebrado fin del gobierno de Rojas Pinilla y la vuelta al poder del bipartidismo. (...) También debemos recordar que los hechos de violencia, a raíz del fenómeno del bandolerismo, determinaron varias reacciones sobre la manera de dar las noticias y explicar sus consecuencias, lo que llevó a debates sobre el papel del periodismo en estas circunstancias. Por tanto, el rechazo a la visibilidad mediática de las acciones criminales, muchas de estas con orígenes políticos, así como las modalidades de censura practicadas por sectores anticomunistas, evidenciaron hasta dónde se podía llegar con tal de defender lo que para algunos supuestamente era la democracia. ${ }^{9}$

Nesse sentido, e para efeito da discussão que pretendemos tecer a longo deste artigo, vale ressaltar o papel cumprido pela violência política colombiana desde os anos de 1950 na conformação das notícias relacionadas ao regime político. Longe de constituir um campo dicotômico ou de simples acomodação diante dos governos, a grande imprensa integra um quadro político em constante deslocamento. Por exemplo, não raro, a defesa da democracia contra o comunismo justificou a omissão da imprensa em relação a violência de Estado. Ao mesmo tempo, o mesmo argumento se prestou à censura de Estado sobre a própria imprensa. Enquanto alguns jornais demonstravam alinhamento editorial inequívoco, a censura crescente nas redações indicava o medo do avanço comunista entre a imprensa.

Nesse jogo político, entretanto, alguns jornais desempenharam papel essencial na preservação dos acordos da Frente Nacional. Ao mesmo tempo em que seus discursos evitaram enfrentamentos violentos entre os dois partidos, também produziram silenciamento de opiniões e comentários sobre o sabido envolvimento dos partidos em assassinatos e ações violentas. Os jornais também evitavam qualquer alusão que favorecesse a visão do Estado como repressor de protestos sociais:

El reporte noticioso de masacres, atropellos a la población civil y el "ambiente revolucionario" inspirado en la revolución cubana, llevó a refinar métodos de censura para perseguir al periodismo que pudiera ser sospechoso de afecto al comunismo. En últimas, si la prensa no estaba con el gobierno, significaba que estaba del lado del

\footnotetext{
${ }^{7}$ Entre eles esteve o Diario Político de Santa Fé, de Bogotá, fundado por Francisco José de Caldas; El Siglo (1849), La Reforma (1851), La Opinión (1863-66), La Paz y El agricultor (1868-69) e La Unión (1861), fundados por Salvador Camacho Roldán; La Democracia, fundado por Rafael Núñez, que também participou dos jornais Neogranadino, El Tiempo y La Opinión.

${ }^{8}$ PRIETO, Nelson C. Más allá de la libertad de prensa: Vicisitudes en la profesionalización de los periodistas colombianos (1950-1975). Doutorado em Historia. Universidad Nacional de Colombia, Bogotá, 2016.

${ }^{9}$ PRIETO, Nelson C. Más allá de la libertad de prensa..., p. 168.
} 
Dentre a citada variedade de folhas que surgiram e desapareceram muito rapidamente durante a história da imprensa colombiana, dois perduram até hoje e são considerados, por alcance $e$ distribuição, os mais importantes do país: El Tiempo e El Espectador. Segundo Prieto ${ }^{11}$, esta gran prensa era composta, principalmente, por jornais bipartidaristas de circulação nacional e regional que apoiaram a coalisão da Frente Nacional.

De acordo com Muñoz ${ }^{12}$ El Tiempo foi fundado em janeiro de 1855 e foi o primeiro jornal de grande formato do país. Os editores se esforçaram para construir um periódico "que servisse de ferramenta ao radicalismo, mas também um órgão literário e noticioso, ao mesmo estilo dos grandes diários europeus". Já El Espectador - fonte para a pesquisa que ora apresentamos -, foi fundado em 1887 por Fidel Cano, na cidade de Medellín. Nos primeiros anos, ainda sob administração familiar, circulou como quinzenário e sofreu diversas interrupções prolongadas até ser, em 1915, transladado a Bogotá. Em 1955, o jornal passou a circular semanalmente, consolidando um estilo mais profissional, em sintonia com aquele que começou a ser adotado em todo o país.

\section{O golpe civil-militar brasileiro de 1964 à luz de El Espectador}

Todo o acervo do jornal colombiano selecionado está disponível na Biblioteca localizada no centro de Bogotá, chamada Luiz Ángel Arango. A busca, feita por meio da consulta a microfilmes, revelou um total de 279 entradas que fazem referência ao golpe civil-militar brasileiro, iniciado em 31 de março de $1964 .{ }^{13}$ Foram examinadas as edições de março - momento imediatamente anterior ao golpe e aquele em que se deflagra o acontecimento; edições do mês de abril - quando se instaura, de fato, o regime de exceção e são produzidas notícias sobre o acontecimento recente; e as publicações de maio período de oficialização da mudança de regime.

El Espectador possuía uma organização interna distribuída, normalmente, em 22 páginas e dividida nas seguintes sessões: a) Diário de la mañana, em que faziam parte os colunistas, as notícias nacionais em destaque, seguidas de notícias internacionais enviadas por agências, e de outras notícias regionais do país; b) Hogar-moda-social, em que estavam os informes de casamentos, mortes e outros eventos sociais; c) Industrial y comercial, com notícias nacionais e internacionais relacionadas à economia, comércio e indústria; e por fim avisos classificados, com a agenda de filmes e também ofertas de emprego, compras e vendas. A sessão dominical, impressa uma vez por semana, apresentava um número maior de páginas, pois oferecia conteúdo cultural e literário aos leitores. Seu custo era de 40 centavos e trazia na capa o seguinte slogan, escrito pelo fundador Fidel Cano: "El Espectador trabalhará para bem da Pátria com critério liberal, e para bem dos princípios liberais com critério patriótico".

A edição $n^{\circ} 20.261$, de $1^{\circ}$ de abril, foi a que concedeu maior destaque à situação brasileira, trazendo desde a capa diversas informações sobre a deposição de Goulart e as mudanças políticas no Brasil.

\footnotetext{
${ }^{10}$ PRIETO, Nelson C. Más allá de la libertad de prensa..., p. 174.

${ }^{11}$ PRIETO, Nelson C. Más allá de la libertad de prensa..., p. 175.

${ }_{12}$ MUNÕZ, Gustavo Otero. Historia del periodismo en Colombia. Santa Fé de Bogotá: Universidad Sergio Arboleda, 1998, p. 86.

${ }^{13}$ A coleta de fontes foi realizada em outubro e novembro de 2016. 


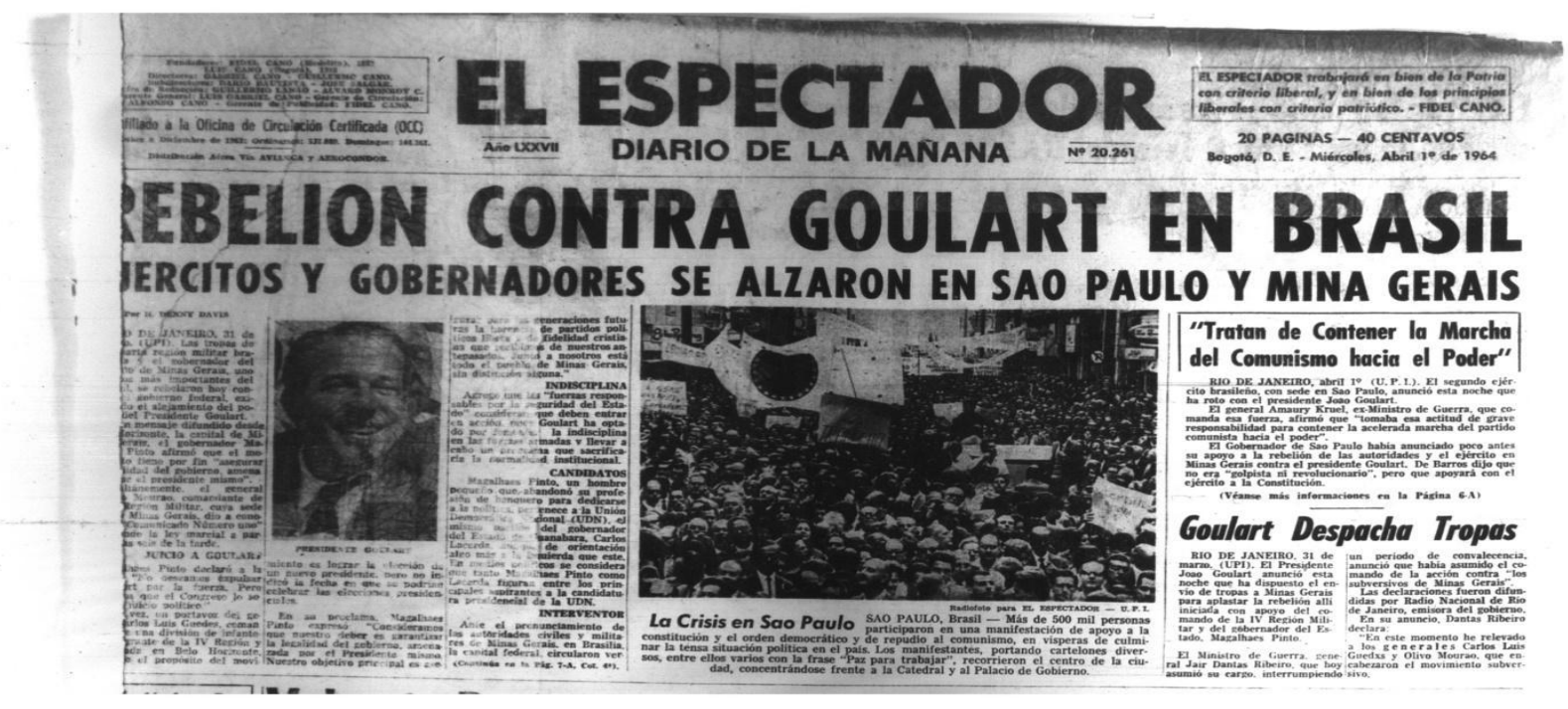

.Figura 1: Capa do jornal El Espectador no dia $1^{\circ}$ de abril, edição n. 20.261: destaque para o início do golpe civil militar brasileiro.

Nota-se na capa a discrepância entre o espaço concedido às possíveis versões acerca dos acontecimentos. A narrativa mais evidente que se pode depreender da leitura desta notícia aponta para os seguintes elementos: trata-se de uma rebelião, e não de um golpe palavra que não aparece em momento algum das várias notícias que compõem a capa acima]; os acontecimentos foram deflagrados por sujeitos politicamente respeitados e defensores da democracia; a figura de João Goulart está associada ao comunismo; grande parte da população apoiou a intervenção. Chama atenção, especialmente, o aspecto identificado como legalista dos fatos ocorridos no Brasil: pequenas chamadas na página anunciam a indisciplina militar alimentada por Goulart, trazem o depoimento de Magalhães Pinto, governador de Minas Gerais e liderança fundamental para os primeiros movimentos de tomada do poder, afirmando a necessidade de assegurar a "legalidade do governo, ameaçada pelo próprio presidente", e ressaltam em imagem e texto a mobilização social em defesa da "Constituição $e$ da ordem democrática, e em repúdio ao comunismo".

O conteúdo da notícia acima descrita nos remete imediatamente a possíveis generalizações historiográficas a respeito da circulação de narrativas sobre o golpe brasileiro na América Latina. Por essa razão, vale lembrar que estamos estabelecendo conexões entre sociedades próximas no tempo e no espaço, que provavelmente exerceram influências recíprocas. Segundo José D'Assunção Barros ${ }^{14}$, a vantagem de comparar sociedades contíguas consiste exatamente em abrir a percepção do historiador(a) para as influências mútuas, o que também o(a) coloca em posição favorável para questionar argumentos causais, iluminando inter-relações. Ainda de acordo com o autor, realidades históricas contíguas permitem a identificação não apenas das semelhanças, mas especialmente das diferenças.

Nesse sentido, podemos afirmar que, de forma geral, a narrativa contida em El Espectador traz elementos mobilizados em grande parte das notícias impressas de quase todos os países latinoamericanos que viveram a experiência dos golpes militares. A aparente contradição da ruptura com a democracia em defesa da democracia pode ser explicada, em grande medida, pelo contexto regional de críticas à democracia à direita e à esquerda durante a década de 1960. Como no Brasil, o processo histórico colombiano também foi marcado pelos questionamentos à democracia social e politicamente desigual, somando-se a isso o contexto global de bipolaridade, lutas por independência em África $e$ Ásia, e especialmente a revolução cubana. Contudo, vale lembrar que, se de parte das chamadas esquerdas radicais, a ruptura com a ordem estava expressa em projetos revolucionários, de parte dos setores conservadores, militares, e/ou alinhados aos Estados Unidos no continente, que contribuíram para a instauração de ditaduras na região, os discursos giraram repetidamente em torno da defesa da democracia, da legalidade e do anticomunismo. Em alguns países como Brasil, Argentina e Chile,

${ }^{14}$ BARROS, José D’Assunção. História Comparada...

170 SÆCUlUM - REVISTA DE HistóRIa [39]; João Pessoa, jul./dez. 2018. 
foram preponderantes, também, os valores cristãos, especialmente, a "manutenção da família tradicional".

No caso da Colômbia, entretanto, entre 1958 e 1974 vigorou um pacto político de "unidade nacional" denominado Frente Nacional. Segundo Jefferson J. Marín ${ }^{15}$, tratou-se, basicamente, de um acordo de partilha dos poderes de governo entre as elites liberais e conservadoras que durou 16 anos. De um lado e de outro, os grupos teriam acordado o compromisso com um triplo desafio institucional: manter a paz, gerar programas de desenvolvimento e favorecer a transição democrática. ${ }^{16}$

De um ponto de vista 'micro' ou específico, é importante salientar que El Espectador mostrou um total de 176 artigos nos três meses analisados, compostos por notícias de agência, colunas opinativas e notícias produzidas pela própria redação. A maior parte derivou de material trazido pela agência United Press Internacional (UPI), por telégrafo. A prática é perceptível pela referência trazida no início de algumas matérias, que mencionam o jornal brasileiro do qual foram retiradas as informações, como, por exemplo, o Jornal do Brasil, bem como a cidade brasileira acompanhada pelas siglas UPI. Isso nos traz um importante complicador: parte das notícias sobre o golpe brasileiro que circularam na Colômbia imediatamente após o acontecimento não foram produzidas internamente, não eram absolutamente narrativas originais. Contudo, consideramos que o ato de reproduzir incide também sobre uma escolha, uma relação fundamental de identificação.

Para melhor visualizarmos a publicação colombiana de capas sobre o golpe civil-militar brasileiro, construímos uma tabela (Tabela $\mathrm{n}^{\circ} 1$ ) onde podem ser observados os títulos das matérias. Nela, figuram de forma sistemática todos os títulos encontrados em El espectador, juntamente à data de publicação e o fornecimento da notícia:

\begin{tabular}{|c|c|c|}
\hline Data & Título & Fonte \\
\hline $31 / 03$ & La Explosiva Crisis em Brasil: Paro Total Anuncia la C.G.T & UPI \\
\hline $1 / 04$ & $\begin{array}{l}\text { Rebelión contra Goulart en Brasil: ejércitos y gobernadores se alizaron en } \\
\text { São Paulo y Minas Gerais (contém foto de João Goulart e de uma manifestação } \\
\text { contra o presidente em São Paulo) }\end{array}$ & UPI \\
\hline $2 / 04$ & Goulart abandonó anoche a Brasilia: organiza resistencia en Porto Alegre & UPI \\
\hline $3 / 04$ & $\begin{array}{c}\text { Huyó Goulart. Mazzilli, Presidente: Uso de los Generales Rebeldes Será el } \\
\text { Presidente por el Resto del Período } \\
\text { (contém foto de João Goulart) }\end{array}$ & UPI \\
\hline \multirow{3}{*}{$4 / 04$} & Em Suspenso el Reconocimiento del Gobierno Brasileño por Colombia & El Espectador \\
\hline & Goulart Va al Uruguay & UPI \\
\hline & Nuevos Ministros de Hacienda y Relaciones Nombrados em el Brasil & UPI \\
\hline $5 / 04$ & $\begin{array}{c}\text { Arrestos em Masa, de Comunistas en el Brasil } \\
\text { (contém foto de Tereza Goulart) }\end{array}$ & UPI \\
\hline $6 / 04$ & $\begin{array}{c}\text { Joao Goulart Dice que Fue Derrocado para Impedir sus Reformas Sociales } \\
\text { (contém foto de Goulart, Tereza e Denise, sua filha) }\end{array}$ & UPI \\
\hline $7 / 04$ & División entre Militares y Civiles Hay em el Brasil & UPI \\
\hline $8 / 04$ & Sangrienta Revolución Comunista Debía Estallar el Dos en el Brasil & UPI \\
\hline 9/04 & Expulsión de Extremistas Aprobó Congreso del Brasil & UPI \\
\hline \multirow{2}{*}{$10 / 04$} & El Golpe Militar en el Brasil: Proclamado "Estado Revolucionario" & UPI \\
\hline & Colombia Reconoció al Gobierno del Brasil & El Espectador \\
\hline $11 / 04$ & El General Kruel Retiró su Candidatura, em Brasil & UPI \\
\hline $12 / 04$ & $\begin{array}{l}\text { Gobierno Militar em el Brasil: Castelo Brasnco, Presidente: continua la } \\
\text { Purga de Izquierdistas (contém foto de general Humberto de A. Castelo Branco) }\end{array}$ & UPI \\
\hline $14 / 04$ & Castelo Branco Assume Formalmente la Presidencia del Brasil, Mañana & UPI \\
\hline $14 / 05$ & Brasil Rompió con Cuba & UPI \\
\hline
\end{tabular}

Tabela 1: Listagem de títulos de matérias publicadas nas capas de El Espectador sobre o golpe brasileiro.

\footnotetext{
${ }^{15}$ MARÍN, Jefferson Jaramillo. Las comisiones de estudio sobre la violencia en Colombia. Un examen a los dispositivos y narrativas oficiales sobre el pasado y el presente de la violencia. In: ALLIER, Eugenia; CRENZEL, Emilio (cord.) Las luchas por la memoria en América Latina. Historia reciente y memoria política. México: Bonilla Artigas Editores : UNAM, Instituto de Investigaciones Sociales, 2015, p. 251.

${ }^{16}$ MARÍN, Jefferson Jaramillo. Las comisiones de estudio sobre la violencia en Colombia...
} 
A partir da observação da tabela, afirmamos que, gradativamente, o acontecimento brasileiro foi sendo definido como 'golpe militar', assim como o governo colombiano acabou por reconhecê-lo como legítimo. Tal "solidariedade" demonstra a preocupação da Frente Nacional em assegurar posição regional solidamente anticomunista. Como se sabe, a bipolaridade mundial definida como oposição - sem ações militares diretas -, entre um bloco europeu e norte americano ocidental que defendia "a democracia e a liberdade", e o bloco oriental com epicentro na União Soviética "socialista", concorreu para inúmeras transformações políticas em contextos locais ou nacionais, contando com setores e elites políticas mais próximas de um ou de outro lado.

No que concerne aos grupos e partidos revolucionários, entre as décadas de 1960 e 70, as Forças Armadas Revolucionárias da Colômbia (FARC), as Forças Armadas de Libertação Nacional (FALN) na Venezuela, o Exército de Libertação Nacional (ELN) na Bolívia, o Movimento de Libertação Nacional Tupamaros (MLN-Tupamaros) no Uruguai, o Partido revolucionário dos Trabalhadores - Exército Revolucionário do Povo (PRT-ERP) na Argentina, o Movimento de Esquerda Revolucionária (MIR) no Chile, e a Organização Revolucionária Marxista Política Operária (ORM-POLOP) no Brasil, entre outras organizações, se constituíram com o intuito de pensar os impasses e as convergências entre as histórias nacionais e a história da região dentro de uma chave socialista. ${ }^{17}$

Nesse mesmo "clima de época", o anticomunismo, como parte das estratégias norte-americanas de influência sobre a América Latina encontrou sólidas bases entre os diversos países da região. Nesse sentido, Rodrigo Patto Sá Motta ${ }^{18}$ afirma que após a revolução cubana em 1959, a nova política norteamericana implicou numa considerável pressão sobre os países da América Latina, na tentativa de estabelecer um "cordão sanitário" capaz de impedir a progressão do comunismo. No entanto, o autor ressalta o equívoco de se pensar o anticomunismo como uma força criada pelos EUA e exportada para a região. Segundo Motta, a tradição anticomunista - no Brasil -, era já uma tendência política de muito poder desde os anos 1930, configurada na existência de grupos constantemente mobilizados contra o "perigo vermelho". ${ }^{19}$

Em artigo intitulado "O golpe militar de 1964 como fenômeno de política internacional", publicado por ocasião dos 30 anos do golpe civil-militar brasileiro, Luiz Alberto Moniz Bandeira ${ }^{20}$ traz outra leitura possível da conjuntura de Guerra-Fria na América Latina. De acordo com o autor, àquele tempo, o que mais afetava, no hemisfério, os interesses de segurança dos Estados Unidos não era exatamente a luta armada pró-comunista, como as guerrilhas na Venezuela e na Colômbia, mas sim o desenvolvimento da própria democracia naqueles países, onde o recrudescimento das tensões econômicas e dos conflitos sociais aguçava a consciência nacionalista, e os sentimentos antinorteamericanos. Moniz Bandeira lembra que em 1962, o então presidente Kennedy havia recebido em audiência o senador Juscelino Kubitschek, ex-presidente do Brasil, e Lleras Camargo, ex-presidente da Colômbia, abordando com eles o tema da América Latina e, em particular, do Brasil. O acontecimento é mencionado pelo autor para destacar a importância dada pelos Estados Unidos ao Brasil como expoente de uma suposta tendência política latino-americana, mas também demonstra o esforço diplomático colombiano em seguir a política internacional de alinhamento estadunidense e a repressão à guerrilha.

Diferente do que ocorreu no Brasil - golpe civil-militar sustentado ideologicamente por desestabilização promovida direta ou indiretamente pelo governo dos Estados Unidos -, o acontecimento marcante e delimitador de fronteiras políticas na Colômbia, foi o chamado Plan Lazo inaugurado no ano de 1964. De acordo com Pablo Ortiz $(2014)^{21}$, Lazo foi o nome dado a um dos planos militares criados entre 1962 e 1966 para frear os movimentos insurrecionais no país. Tratou-se

\footnotetext{
${ }^{17}$ DAHÁS, Nashla. As esquerdas radicais no Brasil e no Chile. Pensamento político, história e memória nos anos de 1960 e 70. Tese de doutorado. Programa de Pós-graduação em História Social do Instituto de Filosofia e Ciências Sociais da UFRJ. Rio de Janeiro-RJ, maio de 2015.

${ }^{18}$ MOTTA, Rodrigo Patto Sá. Em guarda contra o "perigo vermelho": O anticomunismo no Brasil (1917-1964), São Paulo, Perspectiva/FAPESP, 2002.

${ }^{19}$ MOTTA, Rodrigo Patto Sá. Em guarda contra o "perigo vermelho”...

${ }^{20}$ BANDEIRA, Luiz Alberto Moniz. "O golpe militar de 1964 como fenômeno de política internacional". In: TOLEDO, Caio Navarro de. 1964: visões críticas do golpe. Democracia e reformas no populismo. Campinas-SP: EdUnicamp, 2014.

${ }^{21}$ ORTIZ, Pablo Andrés Nieto. El plan "lazo" y el ataque a la "república independiente" de Marquetalia: la puesta en marcha de la doctrina contrainsurgente del Ejército de Colombia, 1962-1966, Revista Historia Crítica, 53, 2014. 
de uma estratégia política e militar para erradicar a chamada subversão. Seu método de ação consistiu na busca reiterada por colaboração popular com as Forças Armadas. Serviços de assistência básica eram oferecidos, como escolas e jornadas de saúde, em troca de apoio civil às ações de repressão $e$ desenvolvimento do Estado. ${ }^{22}$

\section{João Goulart sob as luzes da imprensa}

O personagem em destaque na capa mencionada anteriormente de El Espectador é o presidente brasileiro João Goulart, considerado simpatizante comunista que, por meio de seus aliados $e$ estratégias de implementação de reformas sociais, teria colocado em risco a democracia brasileira. Por essa razão, a figura de Jango é apontada pelas matérias de capa como uma ameaça e é constantemente associada às responsabilidades pela ruptura com a ordem democrática.

Além do acompanhamento de percurso feito pelo presidente deposto entre 31 de março e primeiro de abril de 1964 até o Uruguai, outra matéria de capa explora os motivos de sua derrubada ao dar espaço para falas do próprio João Goulart, bem como de autoridades militares, como se vê abaixo:

Figura 2: Capa do jornal El Espectador no dia 6 de abril: destaque para João Goulart.

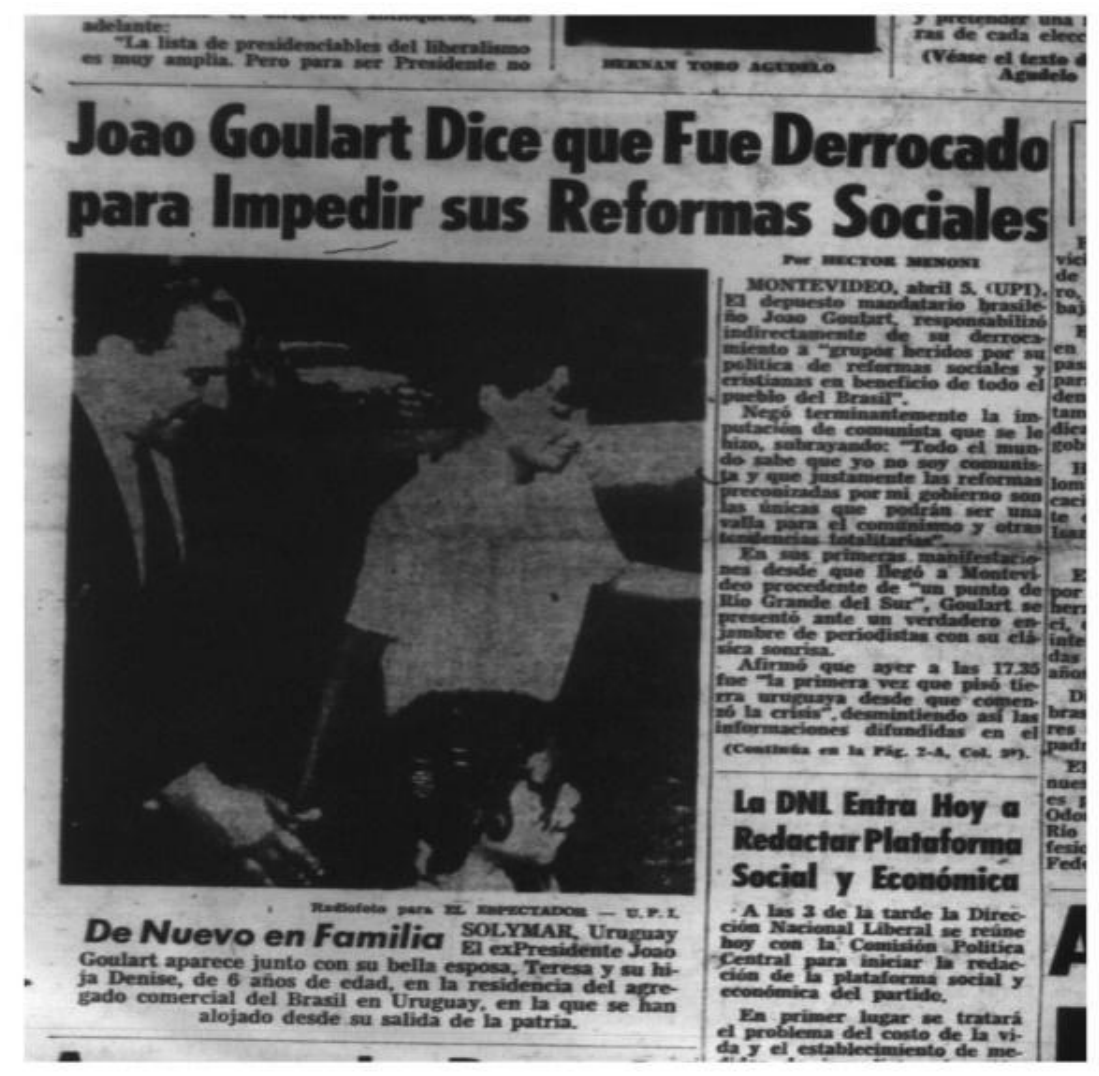

Em entrevista reproduzida na matéria desta capa, Goulart afirma que sua deposição é de responsabilidade direta dos grupos "feridos por sua política de reformas sociais e cristãs em benefício de todo o povo do Brasil". Vale dizer que a nomenclatura de caracterização do golpe brasileiro, assim como as responsabilidades jurídicas e morais por aqueles acontecimentos são ainda hoje objeto de disputas narrativas, historiográficas e políticas no Brasil.

Jango não poderia imaginar a natureza do regime que se seguiria, mas, pode-se dizer que ainda nos anos de 1980, sua impressão registrada no calor dos acontecimentos tornar-se-ia parte da historiografia pelas mãos de Caio Navarro de Toledo $(1991)^{23}$, para quem o golpe de 64 foi eminentemente um golpe contra as reformas de base, entre elas, especialmente, a reforma agrária, a reforma eleitoral, e as propostas de alteração da relação entre governo e empresas multinacionais no

\footnotetext{
${ }^{22}$ ORTIZ, Pablo Andrés Nieto. El plan "lazo" y el ataque a la "república independiente" de Marquetalia...

${ }^{23}$ TOLEDO, Caio Navarro de. O governo Goulart e o golpe de 64. São Paulo: Brasiliense, 11 ed., 1991. SÆCUluM - Revista DE HistóRIa [39]; João Pessoa, jul./dez. 2018.
} 
Brasil. Essa narrativa seria complexificada e questionada pelos próximos 30 anos, haja visto o debate contemporâneo acerca do papel dos(as) civis no golpe, bem como do terrorismo de Estado em democracia como um resquício da ditadura e/ou parte de uma "transição inconclusa" 24 . O fato é que o jornal colombiano permitiu que o presidente brasileiro se manifestasse a respeito dos acontecimentos que o levaram ao exílio. Como em ocasiões anteriores, Goulart reafirmou o caráter cristão e capitalista de seu governo, negando veementemente relações com o comunismo.

De um lado, discursos políticos são estratégias em meio a violentas disputas de poder, de maneira que raramente podem ser compreendidos literalmente. Nenhuma das revoluções que conhecemos se constituiu a partir de um movimento original deliberado nesse sentido. Por outro lado, as propostas de reformas sociais defendidas pelo governo petebista de João Goulart desde fins de 1961 apontam para uma política comum na América Latina dos anos de 1960, de desenvolvimento do capitalismo pela via da industrialização, valorização das pequenas propriedades, com formação de novas camadas de proprietários, sobretudo no mundo rural, incremento da democracia representativa através da inclusão ao direito de voto e controle das remessas de lucro de empresas multinacionais para o exterior. Nessas circunstâncias, consideramos que uma das chaves para compreensão dos acontecimentos, está menos na racionalidade dos discursos abertos do que nos afetos centrais da política brasileira naquele período de Guerra Fria, mobilizados por esses mesmos discursos. O medo do comunismo e da possibilidade de distribuição de bens e riquezas, ou da perda de privilégios relacionados a hierarquias históricas dentro ou fora da caserna assim como o anseio pela manutenção de uma ordem moral confortável para as elites brasileiras, mobilizaram diversos setores sociais que apoiaram o golpe e cujo discurso está marcado por dicotomias como ordem e caos, comunismo e liberdade, democracia e autoritarismo.

\section{Especificidades do contexto político colombiano}

Ainda que partilhasse com o Brasil a mesma atmosfera política geral ligada à Guerra Fria e à influência da Revolução cubana, a Colômbia possui especificidades fundamentais para a compreensão da abordagem da imprensa acerca do golpe de 64 no país vizinho. Não houve no país uma ruptura formal com o Estado de Direito, de maneira que a repressão política e o autoritarismo foram praticados dentro dos quadros da democracia, ou do regime autoritário vigente. A nomenclatura (democracia ou regime autoritário) - vale dizer -, varia conforme a interpretação historiográfica. De todo o modo, como afirmam Eugenia Allier e Emilio Crenzel ${ }^{25}$, é fundamental distinguirmos as características e dimensões da violência política exercida nos marcos dos processos de radicalização política e de instauração de ditaduras militares no Cone Sul (casos de Brasil, Chile e Argentina, por exemplo), daquela conhecida em países como México, Peru e Colômbia - ainda que todos se inscrevam em um mesmo período histórico.

Para melhor compreender esse contexto colombiano, Jefferson Jaramillo Marín propõe um quadro político para a Colômbia da segunda metade do século $\mathrm{XX}$, marcado por três manifestações de violência igualmente impactantes em razão da profundidade das sequelas sociais que deixaram. Segundo o autor:

La primera de esas manifestaciones, conocida como La violencia (1946-1965), se vivió en varias zonas del territorio nacional como un enfrentamiento civil armado entre las dos subculturas políticas de más tradición nacional (liberales y conservadores). Si seguimos los cálculos mínimos de víctimas que se hicieron para la época a partir del matemático e ingeniero Carlos Lemoine y reproducidos en Oquist (1978), este enfrentamiento posiblemente dejó como saldo más de 190.000 víctimas, especialmente campesinos. La segunda de estas manifestaciones, nombrada con cierto prurito metodológico por los expertos como las violencias, fue asociada desde mediados de los años ochenta con diversas modalidades, lógicas y estrategias de uso de la agresión directa para someter, amenazar y eliminar individuos y grupos sociales. A diferencia de La violencia, en el funcionamiento y naturaleza de las violencias no estarían presentes únicamente los móviles políticos y/o partidistas, dado que este tipo de hechos son agenciados y motivados en la mayoría de los casos por empresas del

\footnotetext{
${ }^{24}$ FICO, Carlos. Ditadura militar brasileira: aproximações teóricas e historiográficas...

${ }^{25}$ ALLIER, Eugenia; CRENZEL, Emilio (Cord.) Las luchas por la memoria en América Latina. Historia reciente y memoria política. México: Bonilla Artigas Editores: UNAM, Instituto de Investigaciones Sociales, 2015. 
crimen. Las lógicas, actores y estructuras que potencian estas violencias se manifiestan con especial crudeza en las zonas urbanas, en los centros y periferias, donde logran impactar diferencialmente a sectores vulnerables de la población civil. Expresión estadística de lo anterior la encontramos en las tasas de homicidios que pasarán en el país de 40 por cada 100000 habitantes en 1983, a 70 en 1989 (Camacho y Guzmán, 1990). Además, una característica central de esta modalidad de agresión es haber logrado cooptar y capturar en muchos niveles la institucionalidad democrática del país. La tercera de estas manifestaciones es una especie de interludio entre las dos anteriores, y correspondería a lo que los expertos nombran como conflicto armado interno. $^{26}$

De acordo com esse raciocínio, o golpe de 64 no Brasil ocorre em meio a contexto nacional colombiano não apenas marcado por um enfrentamento civil armado entre as forças antagônicas mais tradicionais do país, responsável por centenas de milhares de mortos especialmente nas zonas rurais, mas também por um momento de transição no que diz respeito à construção de aparatos ilegais de perseguição e assassinatos urbanos, para além da histórica violência estatal. Tal é o contexto do surgimento das insurreições guerrilheiras e da construção do noticiário sobre o golpe militar no Brasil.

Também é importante lembrar que o ano de 1964 ficaria marcado na Colômbia pela criação das Forças Armadas Revolucionárias da Colômbia, organização que se tornaria a guerrilha mais longeva de toda a América Latina.

\section{Considerações finais}

Em um balanço crítico das possibilidades e equívocos de uma História Comparada da América Latina, Maria Ligia Coelho Prado ${ }^{27}$ aponta para a importância da tessitura de conexões globalizantes ou transnacionais, respeitando-se o rigor metodológico e os riscos de narrativas dicotômicas. Diante deste desafio, nos esforçamos por apresentar questões introdutórias a respeito de tema pouquíssimo frequentado por pesquisadores da ditadura brasileira, qual seja: narrativas e olhares construídos por parte da imprensa colombiana a respeito do golpe civil-militar de 1964 no Brasil. Ainda que evidentemente não tenhamos estabelecido uma comparação entre contextos e periódicos, consideramos que dois processos históricos estão em perspectiva, apresentando inter-relações $e$ distanciamentos.

Entendemos a realidade construída pelos periódicos ao grande público como uma fonte fundamental de produção de memória, no sentido da significação e ressignificação dos acontecimentos. Assim, entre março e maio de 1964, é possível observar no periódico colombiano El Espectador a construção de uma narrativa que tende ao conservadorismo incluindo o apoio ao golpe, $e$ à repressão anticomunista. O quadro histórico em que esse processo se realiza, entretanto, é marcado por grandes diferenças entre Brasil e Colômbia à época, como por exemplo, a natureza do regime político estabelecido - o golpe marca a instauração da ditadura brasileira, enquanto a democracia de viés autoritário vige na Colômbia.

É importante considerar que a maior parte da grande imprensa brasileira integrou o heterogêneo conjunto de forças que apoiou o golpe civil-militar de 64, recebendo-o em alguns casos como uma conquista. É hoje, ponto pacífico na historiografia do golpe e da ditadura no Brasil o fato de que a imprensa liberal foi protagonista central da conspiração que derrubou João Goulart. ${ }^{28}$

Consideramos esse um espaço de diálogo $e$ interlocução a partir do qual a historiografia se complexifica e desenvolve. Desta maneira, uma das brechas de nosso artigo consiste na sugestão de que a demonstração da solidariedade latino-americana verificada mais à frente pela Operação Condor (Operação realizada por países do Cone Sul em aliança para repressão internacional da "subversão" entre os anos de 1970 e 80), possui uma história de aproximações e distanciamentos bastante anterior que merece maiores investigações. Essencialmente, reiteramos que a grande imprensa, enquanto órgão privilegiado de circulação de informação e mesmo de significação da realidade, cumpriu papel inequívoco para uma leitura social conservadora daqueles acontecimentos.

\footnotetext{
${ }^{26}$ MARÍN, Jefferson Jaramillo. Las comisiones de estudio sobre la violencia en Colombia..., p. 249.

${ }^{27}$ PRADO, Maria Ligia Coelho. Repensando a história Comparada da América Latina...

${ }^{28}$ NAPOLITANO, Marcos. História do regime militar brasileiro. São Paulo: Contexto, 2014. 


\section{RESUMO}

Este artigo tem o objetivo de apresentar olhares da grande imprensa colombiana sobre o golpe civil-militar brasileiro de 1964. Partimos do cenário histórico colombiano, com suas especificidades políticas, para abordar a experiência jornalística imediata do país relacionada ao golpe no Brasil. Para tanto, apresentaremos os discursos produzidos em um periódico de ampla circulação: El Espectador, tecendo, sempre que possível, relações entre o contexto global, regional $e$ nacional na Colômbia e no Brasil em meados da década de 1960. A análise aponta para a incorporação de narrativas de apoio ao golpe, com destaque para o anticomunismo como argumento central -, embora na Colômbia o regime democrático tenha se mantido formalmente durante todo o período em que vigorou a ditadura no Brasil. Faremos uso da História Comparada como base teórica segundo a qual exemplos estrangeiros, assim como as historiografias dos outros países são considerados como campos fundamentais para ampliação do horizonte das problemáticas.

Palavras-chave: Golpe civil-militar de 1964; El Espectador; História Comparada.

\section{ABSTRACT}

This article aims to present some views of the Colombian press about the Brazilian civilmilitary coup of 1964. We start from the Colombian historical scenario, with political specificities, to approach the country's immediate journalistic experience related to the coup in Brazil. Therefore, we will present the speeches produced in a widely circulated periodical: El Espectador, weaving, whenever possible, relations between the global, regional and national context in Colombia and Brazil in the mid-1960s. The analysis points to the incorporation of narratives in support of the coup, with emphasis on anti-communism as the central argument - although in Colombia the democratic regime was formally maintained throughout the period in which the dictatorship in Brazil prevailed. We will make use of Comparative History as the theoretical basis according to which foreign examples, as well as the historiographies of other countries, are considered as fundamental fields for widening the horizon of the problems.

Keywords: Civil-military coup of 1964; El Espectador; Comparative History.

Artigo recebido em 16 jul. 2018.

Aprovado em 07 set. 2018. 